\title{
Psychopathology
}

Psychopathology 2007;40:93-101

DOI: $\underline{10.1159 / 000098489}$
Received: September 30, 2004

Accepted after revision: October 7, 2005

Published online: January 11, 2007

\section{IREL - A Psychometric Instrument for Measuring Life Themes}

\author{
Philipp Hammelstein ${ }^{\mathrm{a}}$ Ruth Berger ${ }^{\mathrm{b}}$ Martin Buergy $^{\mathrm{a}}$ Peter Fiedler $^{\mathrm{b}}$ \\ Christoph Mundt ${ }^{\text {a }}$ \\ ${ }^{a}$ Psychiatric Hospital and ${ }^{b}$ Psychological Institute, University of Heidelberg, Heidelberg, Germany
}

\section{Key Words}

Autobiographical narratives $\cdot$ Life themes

\begin{abstract}
Background: Although biographical narratives and work involving the meaning of biographical episodes is a central focus in any psychotherapy, there remains a lack of psychometric instruments for measuring the autobiographical construction as such. We will be presenting a theoretical model of an autobiographical construction of life themes and the Interview of Retrospective Exploration of Life themes (IREL) will be used as the basis of a psychometric instrument. The IREL takes about 90$120 \mathrm{~min}$. The interrater reliability and test-retest reliability will be examined. Methods: Two samples of 21 and 23 mentally healthy subjects were recruited. In addition to the IREL, the Beck Depression Inventory (BDI) and SCID were also used to control for psychopathological status and depressive mood. Results: According to our data, biographical events can be explored objectively and reliably using the IREL. Minor test-retest variability of the affective valence of life themes is not state-dependent. Conclusions: Setting aside limitations due to the small sample sizes, the results suggest that the proposed interview is an objective and reliable instrument for measuring central issues within the subjective biographical construction (life themes).

Copyright @ 2007 S. Karger AG, Basel
\end{abstract}

\section{Introduction}

While empirical research regarding human goals and motivation and the way in which these relate to psychopathology has expanded over the last years [see 1], empirical studies concerning the retrospective views of a person's own coherent life history are rare. Phenomological and hermeneutic approaches in European psychiatry for understanding the impact of life events and the specificity of precipitating situations have not yet found their way to becoming objective methods [see 2]. The current lack of research concerning biographical studies may, in part, depend on the difficulty of developing psychometric instruments in order to measure biographical constructions. Furthermore, there is a scarcity of theoretical underpinnings integrating both the empirical results of autobiographical memory research and constructivist considerations into a comprehensive model of exactly how the structures of meaning in life history episodes develop.

In this paper we briefly outline the theoretical model of life themes, which is portrayed in detail elsewhere [3, 4], in order to present first results of a psychometric examination of the Interview of Retrospective Exploration of Life themes (IREL).

\section{KARGER \\ Fax +4161306 1234 E-Mail karger@karger.ch} www.karger.com www.karger.com/psp
Philipp Hammelstein, PhD

Department of Clinical Psychology, Heinrich Heine University

Universitätsstrasse 1 (Geb. 23.03)

DE-40225 Düsseldorf (Germany)

E-Mail philipp.hammelstein@uni-duesseldorf.de 


\section{The Theoretical Model of Life Themes}

Construing one's biography is basically a social action. Biographical narratives, as products of this process, are made for a recipient, even if it is a fictitious one. During construction, the subject needs to recall information which is encoded in the autobiographical knowledge base $[5,6]$, in order to create a coherent story [7]. Personal narratives can be seen as heuristic cornerstones construing a sense of coherence of the past, over the present and into the future $[8,9]$. This is a basic aptitude for organizing experiences and identity [10-12]. Within these narratives, there are recurring themes which contribute substantially to defining the self in terms of qualities and identity over time: we call these life themes. Life themes can thus be defined as cognitive representations of coherent aspects of one's life, which subjectively influence one's experience and behavior at least in a certain lifetime period or throughout life. These cognitive representations are called central themes of the self-memory system by Conway and Pleydell-Pearce [6].

Life themes serve several functions in the social-cognitive system. They function as an ordering structure in the autobiographical knowledge base [5, 13], as an economic way to present and understand biographical narratives and they also form an important part of a person's identity.

The role of the recipient of biographical narratives is not only a passive one. The recipient can for example validate the biographical narrative, influence its creation by asking questions, question aspects of the story and so on. Hence, the emerging story will be formed in part by the recipient. This social modification of the story will in turn start a process of self-reflection and will therefore have an impact on identity. Presumptions such as these form part of any psychotherapeutic approach.

The creation of biographical narratives therefore depends on the motivation of the narrator to feel free to present himself in a specific manner and to allocate a particular meaning to an experience. It also depends on the reactions of the recipient.

Several psychological disciplines have been able to demonstrate that the way in which personal experiences are narrated and gathered through interviews not only affects the specific form of the narratives but also the retrieval, and even the rearrangement and reconstruction of information encoded in the autobiographical knowledge base [14-16]. Modifications of the autobiographical knowledge base are more likely if the content of the narrative is highly important to the person. Therefore, personal memories are not only the sources from which nar- ratives emerge, but also the consequences of biographical narratives.

Life themes, as we have conceptualized them, are part of the conscious explicit memory of the subject, since they are actively constructed when meaning is given to them. In contrast to motives or intrapersonal conflicts, they are not inherent in personal experiences - they have to be created in order to make sense of personal experiences.

By definition, life themes are only moderately affected by change. It would be more appropriate to say that they run through changing lifetime periods like a 'thread'. They do not have an ontological existence outside the individual construction in the sense of an objective quality. It is therefore possible to adapt one's autobiography to new experiences and to change the meaning of former events, thus ensuring that the autobiography is maintained or becomes coherent. This life reflection [17] is a continuing process across an individual's entire life span.

\section{The Construction of IREL}

The semistructured IREL [18] was developed by integrating and adapting several instruments of assessment. ${ }^{1}$ The life history calendar (LHC) [19] was used as a time grid for life themes, and the Computerized Intrapersonal Conflict Assessment (CICA) [20, 21] was employed for labeling the life themes. In addition, we adapted the German version of the Positive and Negative Affect Schedule (PANAS) [original version: 22, German version: 23] to elicit and describe the emotional valence of the life themes. Lastly, we used the List of Exceptional Life Events (LEL) [24] to explore memory landmarks in order to date the life themes.

\section{Life History Calendar}

The LHC is designed to explore retrospective data within a life chart. It has the form of a table, whereby the columns are used as time units (for example years, months or days) and the lines are used for periods of interest (for example, exceptional life events, episodes of disorder, etc.). Data are explored primarily through semistructured interviews. Because biographical data can be recorded reliably even within depressive episodes [25], this approach has been used for many different areas such as the retrospective exploration of abuse [26], the longitudinal

${ }^{1}$ We thank Avshalom Caspi (London, UK), Alexander Grob (Bern, Switzerland), Heinz W. Krohne (Mainz, Germany), and Wolf Lauterbach (Frankfurt, Germany) who gave us permission to adapt their instruments for our purpose. 
Table 1. Examples of the labeled themes used in the IREL

\begin{tabular}{|c|c|c|c|}
\hline \multicolumn{4}{|l|}{ Life themes (selection) } \\
\hline Taking care of one's health & Thinking about one's past & Being calm versus alert & Being aware of negative feelings \\
\hline Therapy & Thoughts about one's own death & Enterprising spirit & Social contacts \\
\hline Being a 'real woman'/'real man' & Dealing with traumatic experiences & Feeling of security/being taken care of & Quality of relationship with * \\
\hline Living according to my values & Quality of home life & Satisfaction with one's body & Independence \\
\hline Well-being of * & Willingness to work & Self-confidence & Acceptance by $*$ \\
\hline Having children & Financial situation & Acknowledging weaknesses & Normal eating behavior \\
\hline Intimate relationship & Advances in work & Sexual needs & Control of the consumption of * \\
\hline Quality of relationship & Self-actualization & Speaking openly about problems & Fear of * \\
\hline Responsibility for $*$ & Satisfying job & & Reducing my * (e.g. pain) \\
\hline
\end{tabular}

* To be replaced by the subjects using their own terms and meanings.

comorbidity in anxiety disorders [27], the course of affective disorders $[28,29]$ and the course of schizophrenic disorders [30]. Belli [31] demonstrated that assessment methods such as the LHC favor the process of retrieving biographical memories: 'The life history calendar encourages an extensive use of the autobiographical memory network, and the multiple paths associated with topdown, sequential, and parallel retrieval strategies' ( $\mathrm{p}$. 395).

For the IREL, we used time periods of 3 months (from the age of 15) and the biographical landmarks we used were moving house, the beginning, change and ending of a relationship, and the birth of a child.

\section{List of Exceptional Life Events}

The LEL was used to explore possible exceptional life events serving as specific biographical landmarks. This list includes 19 life events (e.g. 'death of a relative', 'family quarrel') and 1 joker item for an idiosyncratic critical event. Data concerning the reliability of the LEL have not been reported by Grob [24].

\section{Computerized Intrapersonal Conflict Assessment}

There are at least two possibilities for labeling specific self-defining themes. On the one hand, the subjects could label specific themes themselves without any requirements ('free labeling'); on the other hand, the subjects could select a fixed number of themes from a prepared list of labeled themes. The first possibility comprises one significant difficulty: it is virtually impossible to achieve a homogeneous abstraction level. This is the reason why we chose to use the CICA. In its original version, the CICA is used to measure cognitive dissonance between different current topics ('themes' or 'concepts') over a period of 7 days prior to testing. The list of themes used in the CICA consists of 45 labels of themes which could be of importance, as well as an explanation of the label. Some items contain a symbol which is to be replaced by the subject ('*', e.g. 'fear of *'). The selection of the CICA items was validated by a rating of 80 experts from different countries [clinical psychologists and psychiatrists from different schools in Switzerland, Germany and Russia; see 20,21]. The advantage of this preformulated set of themes for our purpose is the medium abstraction level, which goes along with the highest relevance for the patients; also the origin of the themes from psychotherapies confirms the relevance for psychotherapists, for whom the IREL is conceived. In the IREL, this same list of items was used and complemented by three joker items without a label (see table 1 for examples). Within the IREL the subjects have to date the beginning and end of each theme (question used: 'When did the theme XY begin to be important in your life? Is it important at this time? When did it end? Did it become important once more?').

\section{Positive and Negative Affect Schedule}

The PANAS which consists of 20 items (adjectives) is a questionnaire to measure the affectivity or the mood of a subject in a two-dimensional manner (positive and negative affectivity). The subject rates his mood on a 5-point Likert scale. The reliability and validity of the PANAS have been tested sufficiently [e.g. 32, 33]. The items of the PANAS were used to rate the positive and negative valence of each beginning and end of a specified theme. But it was impossible to rate each beginning and end of a theme in 20 items. We therefore built two 'clouds of emotional adjectives' (a positive and a negative one) each consisting of ten PANAS items, so that the subject could rate how intensively he experienced emotions from the first and the second 'cloud' (from $1=$ not at all to $5=\mathrm{ab}$ solutely). Accordingly, the subject has to remember past 


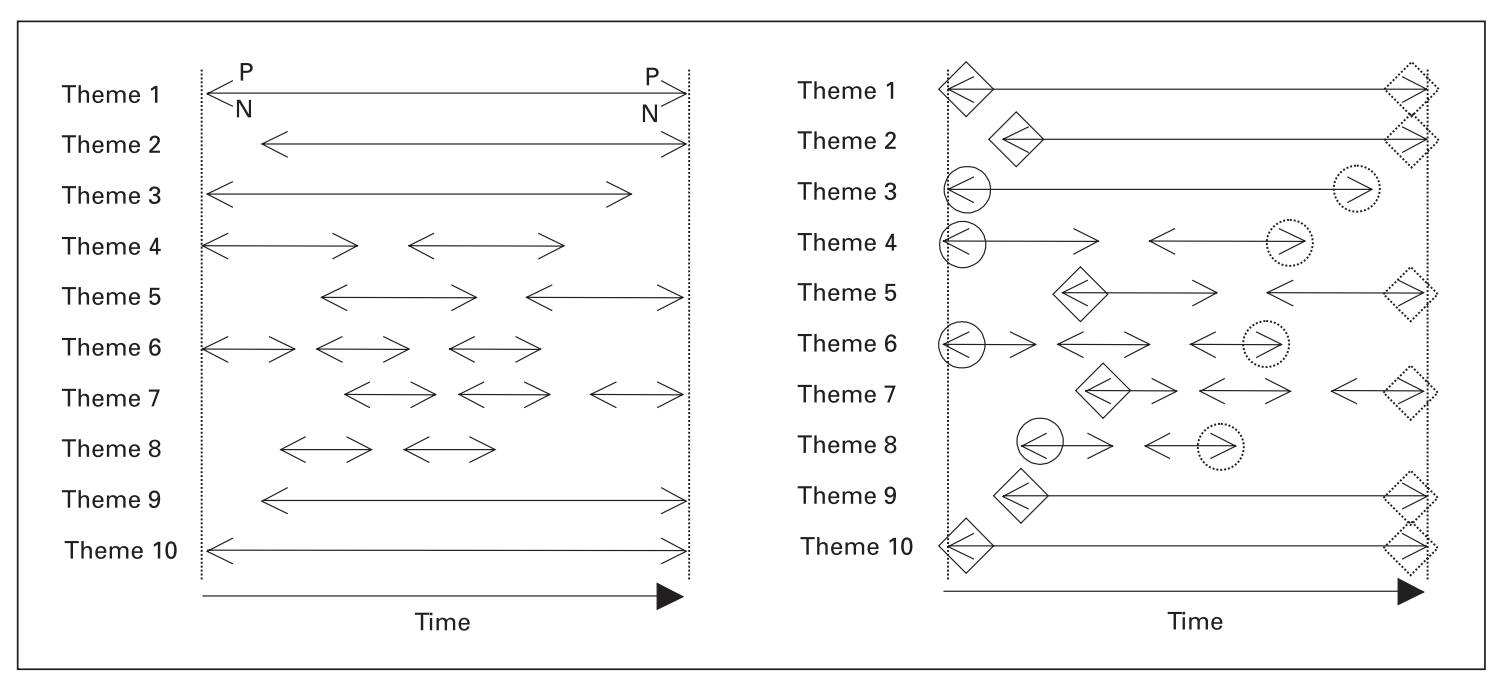

Fig. 1. Graphical description of a subject's fictitious life chart (IREL). Each arrowhead implies a positive as well as a negative value of valence. The procedure for aggregating IREL values is shown on the right. Complete symbols signify beginning values, dotted symbols signify end values. $\diamond=$ Ongoing theme (A theme); $\bigcirc=$ past theme (B theme). $\mathrm{N}=$ Negative valence; $\mathrm{P}$ = positive valence.

emotions which implies a constructive process influenced by current appraisals and mood [34-37].

Application of the IREL implies the following procedure:

1 Selection of the 'ten most important themes of your life' out of the list of 45 presented theme labels (from the age of 15; see table 1). The themes are derived from the CICA [20].

2 Explaining the life chart. The life chart is taken from the LHC [19].

3 Exploration of the living arrangements (e.g. moving house).

4 Beginning, change and end of relationships.

5 Birth of a child.

6 Exceptional life events. The exceptional events are elements of LEL [24].

7 Temporal definition (beginning and possible end) of each life theme.

8 Valence of each life theme at the beginning and end. Subjects rate the emotional valence from two 'emotional clouds' derived from the PANAS [22]. The IREL takes about 90-120 min.

\section{Analysis of Life Themes}

Life themes were classified according to whether they were ongoing (A themes) or past (B themes). Dates of beginning, ending and interception were determined, as well as the emotional valence at the beginning and end of a theme (fig. 1).
The duration of themes was measured as real time duration divided by the total time span covered by the interview. In the case of past themes, duration was calculated by the distance between the ending of the theme and the time of the interview, once again divided by the total time covered by the interview.

\section{Study 1: Testing Objectivity}

The purpose of the first study was to test the interrater reliability (dependence of the output on the interviewer).

A total of 21 mentally healthy subjects (13 females and 8 males) were recruited via an advertisement in a regional newspaper. In this advertisement the subjects were asked to talk to a psychologist about their life. After the interview they were paid EUR 25 each. The subjects ranged in age from 27 to 59 years with a mean age of 41.3 years $(\mathrm{SD}=9.75)$. Mean duration of education was 11.81 years $(\mathrm{SD}=3.20)$. No subject had ever had psychotherapy or suffered from a psychiatric disorder.

The IREL was applied as described above. The German version of the SCID-I was applied [38].

Three interviewers, two female (interviewers A and B) and one male interviewer (interviewer C), were involved. Interviewers $\mathrm{B}$ and $\mathrm{C}$ were $\mathrm{PhD}$ students and interviewer A was a well-trained graduate student of psychology. At time 1, the two female interviewers exam- 
Table 2. Correspondence of the reported frequency concerning biographical landmarks and exceptional life events (ELE) of 21 subjects interviewed by two different interviewers (mean $\pm \mathrm{SD})$

\begin{tabular}{|c|c|c|c|}
\hline & First interview & Second interview & $\mathrm{r}$ \\
\hline \multicolumn{4}{|l|}{ Biographical landmarks } \\
\hline Number of relocations & $5.67 \pm 5.00$ & $5.71 \pm 4.46$ & 0.96 \\
\hline Events concerning marriage & $0.71 \pm 0.46$ & $0.71 \pm 0.46$ & 1.00 \\
\hline Events concerning partner & $6.67 \pm 3.68$ & $5.52 \pm 2.99$ & 0.70 \\
\hline Birth of a child & $1.05 \pm 1.36$ & $1.05 \pm 1.36$ & 1.00 \\
\hline \multicolumn{4}{|l|}{ ELE } \\
\hline Total number of ELE & $7.25 \pm 4.87$ & $6.30 \pm 4.26$ & 0.62 \\
\hline Number of ELE within the last 10 years & $3.60 \pm 2.52$ & $2.80 \pm 1.99$ & 0.75 \\
\hline Number of ELE within the last 5 years & $1.50 \pm 1.24$ & $1.25 \pm 1.07$ & 0.78 \\
\hline Death of spouse & $0.00 \pm 0.00$ & $0.00 \pm 0.00$ & - \\
\hline Death of a child & $0.10 \pm 0.45$ & $0.15 \pm 0.67$ & 1.00 \\
\hline Death of a relative/significant other & $0.70 \pm 0.86$ & $0.80 \pm 1.01$ & 0.84 \\
\hline End of a relationship & $0.90 \pm 1.41$ & $0.60 \pm 0.68$ & 0.56 \\
\hline Loss of job & $0.05 \pm 0.22$ & $0.05 \pm 0.22$ & -0.05 \\
\hline Regular consumption of alcohol/medicine & $0.00 \pm 0.00$ & $0.00 \pm 0.00$ & - \\
\hline Financial problems & $0.00 \pm 0.00$ & $0.15 \pm 0.49$ & - \\
\hline Rejection by significant other & $0.05 \pm 0.22$ & $0.05 \pm 0.22$ & 1.00 \\
\hline Problems because of appearance & $0.20 \pm 0.70$ & $0.30 \pm 0.57$ & 0.37 \\
\hline Serious illness & $0.40 \pm 0.75$ & $0.35 \pm 0.75$ & 0.96 \\
\hline Family quarrels & $0.30 \pm 0.57$ & $0.25 \pm 0.64$ & 0.51 \\
\hline Occupational change & $1.10 \pm 1.94$ & $0.65 \pm 1.39$ & 0.79 \\
\hline Intensive self-reflection & $0.05 \pm 0.22$ & $0.35 \pm 1.14$ & 0.96 \\
\hline Exceptional vacation & $1.35 \pm 2.39$ & $0.80 \pm 1.20$ & 0.30 \\
\hline Pregnancy (unwanted) & $0.70 \pm 1.45$ & $0.50 \pm 1.15$ & 0.76 \\
\hline Children moving away from home & $0.10 \pm 0.31$ & $0.10 \pm 0.31$ & 1.00 \\
\hline Moving house/change of residence & $0.60 \pm 1.05$ & $0.55 \pm 0.89$ & 0.70 \\
\hline Environmental/political events & $0.10 \pm 0.45$ & $0.10 \pm 0.31$ & 0.69 \\
\hline Significant religious events & $0.00 \pm 0.00$ & $0.00 \pm 0.00$ & - \\
\hline Additional events & $0.60 \pm 1.23$ & $0.50 \pm 1.00$ & 0.98 \\
\hline
\end{tabular}

ined 10 and 11 subjects, respectively. In the sense of an incomplete crossover design, the male interviewer $\mathrm{C}$ and the female interviewer A again examined the subjects 7 days later using the IREL only. The interval of 7 days was chosen to minimize memory effects on the one hand, but also to guarantee that the true biographical construction remained quite the same. SCID was used only at time 1.

\section{Results}

Biographical landmarks including exceptional life events reported in the IREL are independent of the interviewer's influence (see table 2). When omitting the three most inconsistent items ('loss of job', 'problems because of personal appearance', 'exceptional vacation') the mean correspondence increases from $r=0.88$ to $r=0.93$.

To test the dating of events, the temporal distance between the event and the date of interview was calculated and divided by the total time covered by the interview. Data were weighted by factor $1 /$ number of exceptional life events per subject. The dating of events correlated at $r=0.97$ between interviewers.

The mean correlation of the selection of themes is Cohen's $\kappa=0.67$. By omitting themes with $\kappa<0.40$ ('willingness to work', 'having children', 'feeling of security') the mean correspondence increases to $\kappa=0.72$. The deviation in the selection of the themes was correlated with the sex of the second interviewer. This correlation is, however, quite marginal $(\Phi=0.22)$.

To test the objectivity of the affective valence and other features of the selected themes, the correlations between the first and the second interview were calculated. Thereby, the correlations (1) of the affective valences of the selected themes, (2) of the duration of the themes and (3) of the time distance to the end of past themes were calculated twice. In the first calculation, all themes were included irrespective of whether they had been selected in one or both interviews. In the second calculation only those themes were included which were selected in both interviews. Table 3 shows the results. 
Table 3. Correspondence of the affective valences, temporal distances to the date of interview and the duration of themes of 21 subjects interviewed by two different interviewers

\begin{tabular}{|c|c|c|c|c|c|c|c|c|}
\hline & \multirow[t]{2}{*}{$\mathrm{n}$} & \multicolumn{2}{|c|}{ Beginning values } & \multicolumn{2}{|c|}{ Ending values } & \multirow[t]{2}{*}{ Distance } & \multirow[t]{2}{*}{ Duration } & \multirow[t]{2}{*}{ Mean $r_{\text {valence }}$} \\
\hline & & positive & negative & positive & negative & & & \\
\hline A themes (all) & 21 & 0.77 & 0.51 & 0.49 & 0.86 & - & 0.96 & 0.70 \\
\hline B themes (all) & 7 & 0.19 & 0.57 & 0.39 & 0.24 & 0.56 & -0.01 & 0.36 \\
\hline A themes (equal only) & 21 & 0.41 & 0.57 & 0.63 & 0.83 & - & 0.88 & 0.64 \\
\hline B themes (equal only) & 7 & 0.79 & 0.39 & 0.77 & 0.33 & 0.90 & 0.17 & 0.61 \\
\hline
\end{tabular}

Calculation is shown to include both groups of themes separately [A themes (all), B themes (all)] and also only those themes which are selected during both interviews [A themes (equal only), B themes (equal only)]. Mean $\mathrm{r}_{\text {valence }}$ shows the mean correspondence of the four affective valences via Fisher's Z transformation.

Duration of themes was measured as real time duration divided by the total time span covered by the interview. In the case of past themes, duration was calculated by the distance between the ending of the theme and the time of the interview, once again divided by total time covered by the interview.

The inclusion of themes selected during both interviews improved only the correspondence of past themes. The reason for this is the low number of subjects using past themes in their biographical construction. Because of the small sample, the correlation coefficients are more easily affected by outliers. The low correlation of $r=0.17$ concerning the duration of $\mathrm{B}$ themes can be reduced to one outlier.

Overall, affective valences and dating of life themes show high interrater reliability. The correlation coefficients of medium size suggest that the subjects modified their affective meaning of life themes slightly, perhaps due to a process of self-reflection during their interviews.

\section{Study 2: Test-Retest Reliability}

The purpose of the second study was to examine the temporal stability of the biographical construction explored by the IREL. Furthermore, we hoped to examine whether the mood during the interviews influences the selection and valence of themes. While it was expected that the reporting of biographical landmarks as well as of exceptional life events would remain stable over time, it was assumed that the affective valences of life themes would be only moderately stable.

A total of 23 mentally healthy subjects (6 female and 17 male subjects) were recruited for the second study, again via an advertisement in a regional newspaper. In this advertisement the subjects were asked to talk to a psychologist about their life. After the second interview the subjects were paid EUR 25 each. Subjects ranged in age from 25.5 to 59 years with a mean age of 41.9 years $(\mathrm{SD}=10.39)$. The mean duration of education was 12.78 years $(\mathrm{SD}=3.38)$. No subject had ever undergone psychotherapy.

The same assessment procedure was used as in study 1. In addition, the subjects were asked to fill out the German version of the PANAS [23] during both interviews. The PANAS should allow us to explore moods over the previous 7 days.

All subjects were interviewed twice by the same interviewer after an interval of 10 weeks. The interviewer was a well-trained female graduate student of psychology.

\section{Results}

After the 10-week interval, biographical landmarks and exceptional life events showed a high stability in the IREL. The strikingly low reliability of the exceptional life event 'death of a child' ( $r=0.10$, see table 4$)$ is due to one female subject having referred to her eight spontaneous abortions as 'death of a child' only in the first interview. If this case is omitted, the reliability of this exceptional life event increases to $r=0.99$. The overall reliability of exceptional life events is $r=0.69$. The dating of events over the 10 weeks correlates at $r=0.99$.

The correspondence of the selection of themes could not be calculated by Cohen's $\kappa$, because $\kappa$ is only applicable when comparing the views of observers, but not when testing retest reliability. Dichotomous variables are normally correlated using the coefficient, but this coefficient is very dependent on heterogeneous marginal fre- 
Table 4. Correspondence of the reported frequency concerning biographical landmarks and exceptional life events (ELE) of 23 subjects interviewed twice within 10 weeks (mean \pm SD)

\begin{tabular}{|c|c|c|c|}
\hline & First interview & Second interview & $\mathrm{r}$ \\
\hline \multicolumn{4}{|l|}{ Biographical landmarks } \\
\hline Number of relocations & $4.83 \pm 2.90$ & $5.09 \pm 2.81$ & 0.84 \\
\hline Events concerning marriage & $1.17 \pm 1.50$ & $1.09 \pm 1.53$ & 0.88 \\
\hline Events concerning partner & $4.87 \pm 3.12$ & $5.26 \pm 3.17$ & 0.90 \\
\hline Birth of a child & $1.90 \pm 2.31$ & $1.90 \pm 2.31$ & 1.00 \\
\hline \multicolumn{4}{|l|}{$E L E$} \\
\hline Total number of ELE & $7.39 \pm 4.21$ & $6.35 \pm 3.32$ & 0.62 \\
\hline Number of ELE within the last 10 years & $3.91 \pm 2.84$ & $3.57 \pm 2.25$ & 0.70 \\
\hline Number of ELE within the last 5 years & $1.87 \pm 1.63$ & $2.00 \pm 1.83$ & 0.59 \\
\hline Death of spouse & $0.05 \pm 0.21$ & $0.09 \pm 0.29$ & 0.69 \\
\hline Death of a child & $0.45 \pm 1.71$ & $0.09 \pm 0.29$ & 0.10 \\
\hline Death of a relative/significant other & $0.43 \pm 0.79$ & $0.61 \pm 0.84$ & 0.82 \\
\hline End of a relationship & $0.96 \pm 0.93$ & $0.70 \pm 0.70$ & 0.61 \\
\hline Loss of job & $0.09 \pm 0.29$ & $0.09 \pm 0.29$ & 0.45 \\
\hline Regular consumption of alcohol/medicine & $0.43 \pm 1.50$ & $0.04 \pm 0.21$ & 0.95 \\
\hline Financial problems & $0.35 \pm 1.07$ & $0.17 \pm 0.49$ & 0.83 \\
\hline Rejection by significant other & $0.00 \pm 0.00$ & $0.04 \pm 0.21$ & - \\
\hline Problems because of appearance & $0.13 \pm 0.46$ & $0.13 \pm 0.46$ & 0.35 \\
\hline Serious illness & $0.09 \pm 0.29$ & $0.09 \pm 0.42$ & 0.69 \\
\hline Family quarrels & $0.35 \pm 0.93$ & $0.30 \pm 0.88$ & 0.42 \\
\hline Occupational change & $0.91 \pm 1.31$ & $0.83 \pm 1.12$ & 0.50 \\
\hline Intensive self-reflection & $0.35 \pm 0.78$ & $0.17 \pm 0.49$ & 0.79 \\
\hline Exceptional vacation & $1.17 \pm 2.44$ & $0.65 \pm 1.03$ & 0.62 \\
\hline Pregnancy (unwanted) & $0.52 \pm 1.16$ & $0.39 \pm 1.12$ & 0.78 \\
\hline Children moving away from home & $0.09 \pm 0.29$ & $0.13 \pm 0.46$ & 0.94 \\
\hline Moving house/change of residence & $0.65 \pm 1.11$ & $1.39 \pm 2.31$ & 0.59 \\
\hline Environmental/political events & $0.13 \pm 0.34$ & $0.22 \pm 0.52$ & 0.85 \\
\hline Significant religious events & $0.04 \pm 0.21$ & $0.08 \pm 0.29$ & 0.69 \\
\hline Additional event & $0.30 \pm 0.76$ & $0.13 \pm 0.46$ & 0.01 \\
\hline
\end{tabular}

quencies, particularly if few yes or no answers exist. This is exactly the case when comparing the selection of ten life themes out of a list of 45 within a 10-week interval: the proportion of negative answers is somewhat larger. Barth and Lienert [39] and Lienert [40] proposed using a modified version of Yule's coefficient $Q$ [41]. This modified version (abbreviated $Q^{\prime}$ ) is corrected for cells with zero values.

After 10 weeks the mean correspondence of the selection of life themes was $Q^{\prime}=0.77$. As in the calculation of interrater reliability, the retest reliability of affective valences, duration of themes and distance to the end of past themes were calculated in two different manners (table 5). With the inclusion of those themes which were selected twice, the retest reliability was evidently higher.

Once again the low value of $r=0.10$ concerning the distance to the negative-valence ending of past themes is due to an outlier; omitting this outlier increases the reliability to $\mathrm{r}=0.62$.
To test the impact of the subjects' mood on assessing affective valences, the duration of themes and the distance of past themes, the residuals of the PANAS (positive and negative mood) were correlated with the corresponding residuals of the IREL (see table 6). Changes in negative moods particularly correspond with changes in the affective valences of the IREL.

\section{Discussion}

The aim of this study was to psychometrically examine an instrument for eliciting and qualifying life themes as fundamental issues of an individual's autobiographical construction. The introduced IREL was tested regarding its objectivity (i.e. interrater reliability) and test-retest reliability within a 10 -week interval.

The highest interrater reliability shows biographical landmarks with mean $r=0.98$ and exceptional life events with $r=0.88$. The duration of and distance to life themes,

Psychopathology 2007;40:93-101 
Table 5. Retest reliability of the affective valences, temporal distances to the date of interview and the duration of themes of 23 subjects interviewed twice within 10 weeks

\begin{tabular}{|c|c|c|c|c|c|c|c|c|}
\hline & \multirow[t]{2}{*}{$\mathrm{n}$} & \multicolumn{2}{|c|}{ Beginning values } & \multicolumn{2}{|c|}{ Ending values } & \multirow[t]{2}{*}{ Distance } & \multirow[t]{2}{*}{ Duration } & \multirow[t]{2}{*}{ Mean $r_{\text {valence }}$} \\
\hline & & positive & negative & positive & negative & & & \\
\hline A themes (all) & 23 & 0.55 & 0.59 & 0.81 & 0.41 & - & 0.92 & 0.62 \\
\hline B themes (all) & 10 & 0.30 & 0.44 & 0.45 & 0.30 & 0.60 & 0.79 & 0.38 \\
\hline A themes (equal only) & 23 & 0.88 & 0.82 & 0.79 & 0.52 & - & 0.84 & 0.78 \\
\hline B themes (equal only) & 7 & 0.95 & 0.87 & 0.65 & 0.10 & 0.94 & 0.90 & 0.77 \\
\hline
\end{tabular}

Calculation is shown to include both groups of themes separately [A themes (all), B themes (all)] and also only those themes which are selected during both interviews [A themes (equal only), B themes (equal only)]. Mean $\mathrm{r}$ valence shows the mean correspondence of the four affective valences via Fisher's Z transformation.

Duration of themes was measured as real time duration divided by the total time span covered by the interview. In the case of past themes, duration was calculated by the distance between the ending of the theme and the time of the interview, once again divided by total time covered by the interview.

Table 6. Relationship between changes in mood and changes in IREL output after 10 weeks

\begin{tabular}{|c|c|c|c|c|c|c|c|c|}
\hline & & \multirow[t]{2}{*}{$\mathrm{n}$} & \multicolumn{2}{|c|}{ Beginning values } & \multicolumn{2}{|c|}{ Ending values } & \multirow[t]{2}{*}{ Distance } & \multirow[t]{2}{*}{ Duration } \\
\hline & & & positive & negative & positive & negative & & \\
\hline \multirow[t]{2}{*}{ A themes } & positive mood & 20 & 0.02 & -0.14 & 0.31 & 0.15 & - & 0.09 \\
\hline & negative mood & 20 & -0.55 & 0.34 & -0.26 & 0.51 & - & 0.13 \\
\hline \multirow[t]{2}{*}{ B themes } & positive mood & 6 & 0.68 & -0.32 & 0.42 & -0.38 & -0.06 & -0.43 \\
\hline & negative mood & 6 & -0.77 & 0.14 & -0.35 & 0.27 & -0.07 & 0.52 \\
\hline
\end{tabular}

Calculation is shown using the residuals of PANAS and the residuals of IREL values (including only those themes selected during both interviews).

which are often examined retrospectively, can also be explored objectively. The affective valence allocated to a theme correlates at a somewhat lower level of $r=0.64$ for ongoing themes and $\mathrm{r}=0.61$ for past themes.

This somewhat moderate correlation could be due to changes in the affective state. However, overall it seems that time does not have as great an effect on the biographical construction as a change in interviewer does. Nonetheless, the presented results must be interpreted with caution due to the small number of subjects.

Within this study, the validity of the IREL was not tested. This, in part, is due to the fact that the various components of the IREL can potentially be examined in content, and also, in part, because studies could be devised which would test derived hypotheses concerning life themes and autobiographical construing. However, we refer to the validation of the labels by Lauterbach [20, 21] as 'central themes within psychotherapy' being rated by experts, which suggests a 'pragmatic validity'.
Understanding the molding of meaning in a life history and its transformation in psychotherapy is a central topic of every therapeutic orientation [42]. According to our data the IREL is in a position to help us achieve this understanding.

\section{Acknowledgment}

We would like to thank the Deutsche Forschungsgemeinschaft for supporting this study by the Postgraduate Program of Clinical Research on Emotion. Furthermore, we would like to thank Sandra Bausch and Anke Reimann for interviewing participants. 


\section{References}

1 Schmuck P, Sheldon KM: Life Goals and WellBeing. Toward a Positive Psychology of Human Striving. Seattle, Hogrefe, 2001.

2 Jaspers K: Allgemeine Psychopathologie, ed 5. Berlin, Springer, 1948.

3 Hammelstein P, Fiedler P: Biographische Narrative und Lebensthemen - Relevanz für Klinische Psychologie und Psychotherapie. Verhaltensther Verhaltensmed 2002;23:307328.

-4 Bürgy M, Mundt C: Methodenprobleme der Biographieforschung über Lebensthemen. Z Klin Psychol Psychiatr Psychother 2000;48: 329-342.

5 Conway MA: Autobiographical knowledge and autobiographical memories; in Rubin DC (ed): Remembering Our Past. Studies in Autobiographical Memory. New York, Cambridge University Press, 1996, pp 67-93.

6 Conway MA, Pleydell-Pearce CW: The construction of autobiographical memories in the self-memory system. Psychol Rev 2000;107: 261-288.

7 Barclay CR: Autobiographical remembering: narrative constraints on objectified selves; in Rubin DC (ed): Remembering Our Past. Studies in Autobiographical Memory. New York, Cambridge University Press, 1996, pp 94125.

8 Bluck S, Habermas T: Extending the study of autobiographical memory: thinking back about life across the life span. Rev Gen Psychol 2001; 5:135-147.

9 Ramsay JR: Postmodern cognitive therapy: cognitions, narratives, and personal meaningmaking. J Cogn Psychother 1998;12:39-55.

10 Freeman M: Culture, narrative and the poetic construction of selfhood. J Constructivist Psychol 1999;12:99-116.

11 McAdams DP: The psychology of life stories. Rev Gen Psychol 2001;5:100-122.

12 Polkinghorne DE: Narrative and self-concept. J Narrative Life History 1991;1:135-153.

13 Conway MA: The inventory of experience: memory and identity, in Pennebaker JW, Paez D, Rimé B (eds): Collective Memory of Political Events: Social Psychological Perspectives. Hillsdale, Lawrence Erlbaum, 1997, pp 2145.

14 Belli RF, Loftus EF: The pliability of autobiographical memory: misinformation and the false memory problem; in Rubin DC (ed): Remembering Our Past. Studies in Autobiographical Memory. New York, Cambridge University Press, 1996, pp 157-179.
15 Conway MA, Collins AF, Gathercole SE, Anderson SJ: Recollections of true and false autobiographical memories. J Exp Psychol Gen 1996;125:69-95.

16 Schacter DL, Dodson CS: Misattribution, false recognition and the sins of memory. Philos Trans R Soc Lond B Biol Sci 2001;356:13851393.

17 Staudinger UM: Life reflection: a social-cognitive analysis of life review. Rev Gen Psychol 2001;5:148-160.

18 Hammelstein P, Berger R, Bürgy M, Mundt C, Fiedler P: Interview zur retrospektiven Erfassung von Lebensthemen. IREL. Manual zur Erhebung und Auswertung (unpubl. manuscript), Universität Heidelberg, 2000.

19 Caspi A, Moffitt TE, Thornton A, Freedman D, Amell JW, Harrington H, Smeijers J, Silva PA: The life history calendar: a research and clinical assessment method for collecting retrospective event-history data. Int J Methods Psychiatr Res 1996;6:101-114.

20 Lauterbach W: The measurement of personal conflict. Psychother Res 1996;6:213-225.

21 Lauterbach W, Newman CF: Computerized intrapersonal conflict assessment in cognitive therapy. Clin Psychol Psychother 1999;6:357374.

22 Watson D, Clark LA, Tellegen A: Development and validation of brief measures of positive and negative affect. J Pers Soc Psychol 1988;54:1063-1070.

23 Krohne HW, Egloff B, Kohlmann C-W, Tausch A: Untersuchung mit einer deutschen Version der 'Positive and Negative Affect Schedule' (PANAS). Diagnostica 1996;42:139-156.

24 Grob A: Subjective well-being and significant life-events across the life span. Swiss J Psychol 1995;54:3-18.

- 25 Bühler K-E, Haltenhof H, Geyer S, Bardeleben H: Reliability of biographical data, their relations to personality variables and their influence on life-events. J Affect Disord 1999;53: 67-76.

26 Gest SD, Reed M-GJ, Masten AS: Measuring developmental changes in exposure to adversity: a life chart rating scale approach. Dev Psychopathol 1999;11:171-192.

27 Hunt C, Andrews G: Comorbidity in the anxiety disorders: the use of a life-chart approach. J Psychiatr Res 1995;29:467-480.

28 Cutler NR, Post RM: Life course of illness in untreated manic-depressive patients. Compr Psychiatry 1982;23:101-115.

-29 Roy-Byrne P, Post RM, Uhde TW, Porcu T, Davis D: The longitudinal course of recurrent affective illness: life chart data from research patients at the NIMH. Acta Psychiatr Scand 1985;71:1-34.
30 Harding CM, McCormick RV, Strauss JS, Ashikaga T, Brooks GW: Computerised life chart methods to map domains of function and illustrate patterns of interactions in the longterm course trajectories of patients who once met the criteria for DSM-III schizophrenia. $\mathrm{Br}$ J Psychiatry 1989;155:100-106.

31 Belli RF: The structure of autobiographical memory and the event history calendar: potential improvements in the quality of retrospective reports in surveys. Memory 1998;6:383406.

32 Mackinnon A, Jorm AF, Christensen $\mathrm{H}$, Korten AE, Jacomb PA, Rodgers B: A short form of the Positive and Negative Affect Schedule: evaluation of factorial validity and invariance across demographic variables in a community sample. Pers Individ Differ 1999; 27:405-416.

33 Melvin G, Molloy GN: Some psychometric properties of the Positive and Negative Affect Schedule among Australian youth. Psychol Rep 2000;86:1209-1212.

34 Christianson SÅ: Remembering emotional events: potential mechanisms; in Christianson SÅ (ed): The Handbook of Emotion and Memory: Research and Theory. Hillsdale, Lawrence Erlbaum, 1992, pp 307-340.

35 Levine LJ: Reconstructing memory for emotions. J Exp Psychol Gen 1997;126:165-177.

- 36 Levine LJ, Prohaska V, Burgess SL, Rice JA, Laulhere TM: Remembering past emotions: the role of current appraisals. Cogn Emotion 2001;15:393-417.

37 Christianson SÅ, Safer MA: Emotional events and emotions in autobiographical memories; in Rubin DC (ed): Remembering Our Past. Studies in Autobiographical Memory. New York, Cambridge University Press, 1996, pp 218-243.

38 Wittchen H-U, Zaudig M, Fydrich T: Strukturiertes klinisches Interview für DSM-IV. Achse I und II. Handanweisung. Göttingen, Hogrefe, 1997.

39 Barth A-R, Lienert GA: Testkonstruktion: Aufgaben- und Probandenanalyse (TC-Analyse) mittels Yule-Koeffizienten. Psychol Beitr 1986;28:366-374.

40 Lienert GA: Testaufbau und Testanalyse, ed 4. Weinheim, Beltz, 1989.

41 Yule GU: On the association of attributes in statistics: with illustrations from the material of the childhood society. Philos Trans Phys Sci Eng 1900;194:257-319.

42 Brewin CR, Power MJ: Integrating psychological therapies: processes of meaning transformation. Br J Med Psychol 1999;72:143-157. 